East European Journal of Physics

East Eur. J. Phys. 3. 31-38(2020)

DOI:10.26565/2312-4334-2020-3-04

PACS: $12.40 . \mathrm{Yx}, 14.40 . \mathrm{Pq}, 02.60 . \mathrm{Cb}, 12.39 . \mathrm{Jh}, 14.65 . \mathrm{Dw}, 14.40 . \mathrm{Lb}, 14.80 . \mathrm{Bn}$

\title{
CHARMONIUM PROPERTIES
}

\author{
Tarek A. Nahool ${ }^{\mathrm{a}, *}$, A.M. Yasser ${ }^{\mathrm{b}, * *}$, Muhammad Anwar ${ }^{\mathrm{a}}$, Gamal A. Yahya ${ }^{\mathrm{a}}$ \\ ${ }^{a}$ Physics Department, Faculty of ScienceAswan University, Egypt \\ ${ }^{b}$ Physics Department, Faculty of Science at Qena, South Valley University, Egypt \\ Corresponding Authors: *tarek.abdelwahab@sci.svu.edu.eg,**Yasser.mostafa@sci.svu.edu.eg
}

Receive February 29, 2020; revised June 19, 2020; accepted June 25, 2020

\begin{abstract}
We calculated the mass spectra of charmonium meson by using matrix method to make the predictions of ground and radially excited states of charmonium mesons via non-relativistic potential model. We compared our results with other theoretical approaches and recently published experimental data. The predictions are found to be in a good accordance with the latest experimental results of Particle data group and with the results of other theoretical approaches. Besides, we calculated the momentum width coefficients $\beta$ of charmonium meson. Since, there are no experimental data for the momentum width coefficients $\beta$ of charmonium meson yet. Consequently, our calculated coefficients $\beta$ are compared with other theoretical studies and it is found to be in a good agreement with our results. The obtained results of coefficients $\beta$ have implications for decay constants, decay widths and differential cross sections for charmonium system and generally for heavy mesons system. Our study is considered as theoretical calculation of some properties of charmonium meson.
\end{abstract}

KEYWORDS: heavy mesons, matrix method, charmonium, momentum width

Charmonium is a group of fundamental particles that are held to consist of a charmed quark-antiquark pair. The lowest bound state of a charm and anti-charm quark is called the $\mathrm{J} / \psi$, whose mass is about 3.5 times greater than the proton mass. The $c \bar{c}$ meson presents itself as an ideal system to test assumptions of QCD. By making precise measurement of the masses, widths, and branching ratios of charmonium states important information about the dynamics of quark anti-quark interaction can be extracted [1]. The charmonium systems may provide unique signs to the non-perturbative behavior of QCD in the low-energy regime and have attracted a great deal of care from the quarkonium physics community [2]. In 2007, the Belle Collaboration [3] reported the Y (4660) resonance, as the heaviest state among the charmonium-like states at present for the first time. Its mass was determined to be $\mathrm{M}=(4664 \pm$ 16) $\mathrm{MeV}$. In the past decade, the properties of the charmonium states were widely explored with various theoretical methods. Reliable perturbative approaches, like lattice QCD [4], heavy quark effective field theory [5] and potential models are trying to explain the phenomena of quark confinement and dynamics of QCD. Charmonium is produced in various reactions, and subsequently decays into other particles. Studying its production mechanism will give a prolific testing for the QCD. There are many potential models commonly used to study heavy quarkonium spectra [6-9]. One of the most successful potential for such systems is the non-relativistic potential model [10-13]. We adopt the Cornell plus hyperfine correction plus spin-dependent terms model [14] to accurately obtain the $c \bar{c}$ spectrum of quark interactions for $\mathrm{S}$ and $\mathrm{P}$ states. Then, we compare our present work to other theoretical approaches $[15,16]$ and experimental results [17] to stress the success of our model. On the other hand, the main motivation is to calculate the numerical values of coefficient $\beta$ that is related to the root-mean-square radius of quarkonium for different states of $c \bar{c}$ meson. Momentum width parameter $\beta$ can be used to calculate the decay widths [18], and differential cross sections [19] for quarkonium states. The produced calculations of the momentum width parameter $\beta$ are compared with published theoretical calculations from [20,21]. The main aim of this research is to study the spectrum of charmonium meson using the matrix method [22]. Moreover, we compute the numerical values of coefficient $\beta$ for conventional charmonium mesons and compare the obtained results with recently published calculations. The chief advantage of our perspective method is that all the computational process, requires a remarkably little time. Our method is overwhelmingly easy and fast, and it gives very accurate results.

This article is organized as follows. In Section 1 we present some characteristics properties of charmonium mesons which in turn depend on the potential model, details of the used methods in our present work are given in Section 2. Results and discussion are given in Section 3. Finally, in the last section, we summarize our main results and conclusions.

\section{Characteristics of charmonium mesons 1.1 The constituent potential model}

One of the most successful ways of describing the mesonic system is to solve the non-relativistic Schrödinger equation for these quark-anti quark states with an appropriate potential model. In a non-relativistic constituent quark model, the non-relativistic description with the Schrödinger equation gives acceptable results. We used the standard color Coulomb plus linear scalar form, and also include contact hyperfine interaction then We treated the remaining spin-dependent terms as mass shifts using leading-order perturbation theory. Thus, the potential model used here can be written as [1]: 


$$
V(r)=\frac{-4 \alpha_{s}}{3 r}+b r+\frac{32 \pi \alpha_{s}}{9 m^{2} c} \delta(\vec{r})\left(\overrightarrow{S_{c}} \cdot \overrightarrow{S_{\bar{c}}}\right)+\frac{1}{m_{c}^{2}}\left[\left(\frac{2 \alpha_{s}}{r^{3}}-\frac{b}{2 r}\right) \vec{L} \cdot \vec{S}+\frac{4 \alpha_{S}}{r^{3}} T\right]
$$

where

$$
\delta(\vec{r})=\left(\frac{\sigma}{\sqrt{\pi}}\right)^{3} e^{-\sigma^{2} r^{2}}
$$

and $\mu$ is the reduced mass of the quark and anti-quark

$$
\mu=\frac{m_{c} m_{\bar{c}}}{m_{c+} m_{\bar{c}}} .
$$

Here $\alpha_{s}$ is the quark-gluon coupling, $\left(\frac{-4}{3}\right)$ is the appropriate color factor and (b) is the parameter of the string tension, and $(r)$ is the distance between the quarks; $m_{c}$ is the mass of the charm quark, and the last term is for the spin-orbit potential with where $s$ is the total spin quantum number of the meson [24] and

$$
\overrightarrow{S_{c}} \cdot \overrightarrow{S_{\bar{c}}}=\frac{S(S+1)}{2}-\frac{3}{4} \text {. }
$$

The last term is for the spin-orbit potential with

$$
\langle\vec{L} . \vec{S}\rangle=\frac{[J(J+1)-(L(L+1)-S(S+1))]}{2} .
$$

The spin-orbit operator is diagonal in a $\mid J, L, S>$ basis with the matrix elements. The tensor operator $T$ [25] has non vanishing diagonal matrix elements only between $L>0$ spin-triplet states, which are

$$
T=\left\{\begin{array}{c}
-\frac{L}{6(2 L+3)}, J=L+1 \\
+\frac{1}{6}, J=L \\
-\frac{(L+1)}{6(2 L-1)}, J=L-1
\end{array} .\right.
$$

For the charmonium mesons, the parameters $\alpha_{s}, \mathrm{~b}, \sigma$, and $m_{\mathrm{c}}$ are taken from [26] to be $0.4942,0.1446 \mathrm{GeV}^{2}, 1.1412$ $\mathrm{GeV}$ and $1.4619 \mathrm{GeV}$, respectively.

\subsection{The Radial Wave Functions of Charmonium Mesons}

Charmonium mesons can be described by the wave function of the bound state of quark-antiquark. This wave function $\psi(r)=r R(r)$ can be found by solving the time independent Schrödinger equation for a particle of reduced mass $\mu$ moving in a spherically symmetric potential with a position vector $r \vec{r}$ and it is can be expressed as:

$$
\left[-\frac{\hbar^{2}}{2 \mu} \Delta+V(r)\right] \psi(\vec{r}, \theta, \varphi)=E \psi(\vec{r}, \theta, \varphi) .
$$

In spherical coordinates the Schrodinger equation takes the form

$$
\left[\left(-\frac{\hbar^{2}}{2 \mu} \frac{1}{r} \frac{d^{2}}{d r^{2}} r+\frac{1}{2 \mu} \frac{1}{r^{2}} \widehat{\widehat{L^{2}}}\right)+V(r)\right] \psi(\vec{r}, \theta, \varphi)=E \psi(\vec{r}, \theta, \varphi)
$$

where $\hat{\vec{L}}$ is orbital angular momentum and $(r)$ is the distance between the quarks.

Dividing the last equation into two parts, the first part is the radial kinetic energy and the second term is the potential energy.

The radial part can be written as

$$
\left[-\frac{\hbar^{2}}{2 \mu}\left(\frac{1}{\mathrm{r}} \frac{\mathrm{d}^{2}}{\mathrm{dr}^{2}} \mathrm{r}-\frac{\mathrm{l}(\mathrm{l}+1)}{\mathrm{r}^{2}}\right)+V(r)\right] R(r)=E R(r),
$$

Then

$$
\psi(r)=r R(r)
$$

The matrix method [27] is used to solve Schrödinger to get the spectrum of charmonium, the details of this method could be found in the following section. 


\subsection{The momentum width coefficient $\beta$}

The meson wave function is characterized by a momentum width parameter $\beta$ that is depending upon the angular momentum quantum numbers and related to the root mean square radius quark-anti quark separation $r_{m s}$ of the meson by [28].

$$
\beta=\sqrt{2(n-1)+(L)+\frac{3}{2}} \frac{1}{r_{m s}} .
$$

Since, the root mean square radius $r_{m s}$ depends on the wave functions $\psi(r)$, which results from solving Schrödinger equation by using our method, it is expected that, the $\beta$ values will be very accurate.

\section{Matrix method for solving Schrödinger equation}

Matrix method is a numerical approach for solving the Schrodinger Equation where the eigenvalues of a matrix gives the total energies of the particle (spectra) and the Eigen functions are the corresponding wave functions. Let us re write the Schrodinger equation in Eq. (9) using natural units.

Then it will be expressed as:

$$
-\frac{1}{2 \mu} \frac{d^{2} \psi}{d r^{2}}+\left[V(r)+\frac{l(l+1)}{2 \mu r^{2}}\right] \psi(r)=E \psi(r)
$$

Next, the second derivate of $\psi(r)$ function takes the form

$$
\frac{d^{2} \psi(r)}{d r^{2}}=\frac{\psi(r+h)-2 \psi(r)+\psi(r-h)}{h^{2}}+O\left(h^{2}\right)
$$

here,

$$
h=\frac{R_{\max }-R_{\min }}{N},
$$

where $h$ is our step between two points, $R_{\min }$ and $R_{\max }$, are minimum and maximum values for the variable $(r)$ respectively with a given number of steps $(\mathrm{N})$ all over the range.

We can rewrite the Schrödinger equation in Eq. (12) for $r_{i}$ as follow:

$$
-\frac{\psi\left(r_{i}+h\right)-2 \psi\left(r_{i}\right)+\psi\left(r_{i}-h\right)}{2 \mu h^{2}}+\left[V\left(r_{i}\right)+\frac{l(l+1)}{2 \mu r_{i}^{2}}\right] \psi\left(r_{i}\right)=E \psi\left(r_{i}\right)
$$

where, $r_{i}=R_{\min }+i h, i=1,2, \ldots \ldots, N-1$

Let us use a compact way of writing the previous equation as:

$$
-\frac{\psi_{i+1}-2 \psi_{i}+\psi_{i-1}}{2 \mu h^{2}}+\left[V\left(r_{i}\right)+\frac{l(l+1)}{2 \mu r^{2}}\right] \psi_{i}=E \psi_{i}
$$

where, $\psi_{i}=\psi\left(r_{i}\right), \psi_{i+1}=\psi\left(r_{i}+h\right), \psi_{i-1}=\psi\left(r_{i}-h\right)$

The last equation could be written as:

$$
c_{\mathrm{i}} \psi_{i+1}+d_{i} \psi_{i}+c_{\mathrm{i}} \psi_{i-1}=E \psi_{i}
$$

Where

$$
d_{i}=\left[\frac{1}{\mu h^{2}}+V\left(r_{i}\right)+\frac{l(l+1)}{2 \mu r^{2}}\right], \quad c_{i}=-\frac{1}{2 \mu h^{2}}
$$

Where $d_{i}$ and $c_{i}$ represent the diagonal and non-diagonal elements, respectively.

Eq. (17) could be transformed into a matrix form. Thus, we can rewrite it as a group of linear equations as follows:

$$
\begin{array}{ccccccc}
c_{1} \psi_{2} & + & d_{1} \psi_{1} & + & c_{1} \psi_{0} & = & E \psi_{1} \\
c_{2} \psi_{3} & + & d_{2} \psi_{2} & + & c_{2} \psi_{1} & = & E \psi_{2} \\
c_{3} \psi_{4} & + & d_{3} \psi_{3} & + & c_{3} \psi_{2} & = & E \psi_{3} \\
\vdots & \vdots & \vdots & \vdots & \vdots & \vdots & \vdots \\
\vdots & \vdots & \vdots & \vdots & \vdots & \vdots & \vdots \\
c_{\mathrm{N}} \psi_{N+1} & + & d_{N} \psi_{N} & + & c_{N} \psi_{N-1} & = & E \psi_{N}
\end{array}
$$


Then the matrix takes the diagonal form as:

$$
\left(\begin{array}{cccccccc}
\mathrm{d}_{1} & \mathrm{c}_{2} & 0 & 0 & \ldots & \ldots & 0 & \ldots \\
\mathrm{c}_{1} & \mathrm{~d}_{2} & \mathrm{c}_{3} & 0 & \ldots & \ldots & 0 & \ldots \\
0 & \mathrm{c}_{2} & \mathrm{~d}_{3} & \mathrm{c}_{4} & \ldots & \ldots & \ldots & \ldots \\
\ldots & \ldots & \ldots & \ldots & \ldots & \ldots & \ldots & \ldots \\
\ldots & \ldots & \ldots & \ldots & \ldots & \mathrm{d}_{\mathrm{N}-1} & \mathrm{c}_{\mathrm{N}-1} & \ldots \\
\ldots & \ldots & \ldots & \ldots & \ldots & \mathrm{c}_{\mathrm{N}-1} & \mathrm{~d}_{\mathrm{N}-1} & \mathrm{c}_{\mathrm{N}}
\end{array}\right)\left(\begin{array}{c}
\psi_{1} \\
\psi_{2} \\
\psi_{3} \\
\ldots \\
\psi_{N-2} \\
\psi_{N-1}
\end{array}\right)=E\left(\begin{array}{c}
\psi_{1} \\
\psi_{2} \\
\psi_{3} \\
\ldots \\
\psi_{N-2} \\
\psi_{N-1}
\end{array}\right)
$$

This is a tridiagonal matrix of dimension $(N-1) x(N-1)$, then this matrix can be solved as an eigenvalue problem and yields $(N-1)$ eigenvalues. We implemented our method to solve eigenvalue problems.

\section{Results and discussion}

In this article we have calculated the spectra of $\mathrm{S}$ and $\mathrm{P}$ wave states of charmonium meson by solving the Schrödinger equation numerically using matrix method. Coulomb plus linear plus hyperfine plus spin-dependent terms potential model are considered. By taking $\mathrm{N}=200, R_{\max }=20 \mathrm{fm}, \alpha_{s}(c)=0.4942, b=0.1497 \mathrm{GeV}^{2}, \sigma=$ $1.1412 \mathrm{GeV}$ and the charm quark mass $=1.4619 \mathrm{GeV}$ for S-states and for P-states, the spectra were summarized in Tables $(1,2)$. We predict the masses of the twenty states of $c \bar{c}$ meson where we compared our theoretical predictions with those from $[15,16,17]$. By comparing present work with the recently published experimental data, we found that the maximum errors are $0.03 \mathrm{GeV}$ for S-states and the maximum errors for P-states are $0.044 \mathrm{GeV}$. Similarly, we found that the maximum errors between our work and [15] are $0.03 \mathrm{GeV}$ for S-states and P-states. In the same way, we calculate the maximum errors between our work and [16] and it was $0.02 \mathrm{GeV}$ for S-states and $0.03 \mathrm{GeV}$ for P-states. Hence, it can be seen that our calculated spectra are in close accordance with the PDG results and with the results of other theoretical studies, thus it can be concluded that this method gives satisfying results for predicting charmonium spectra. The normalized radial wave functions for charmonium mesons are graphically represented in Figures (1) and (2) respectively.

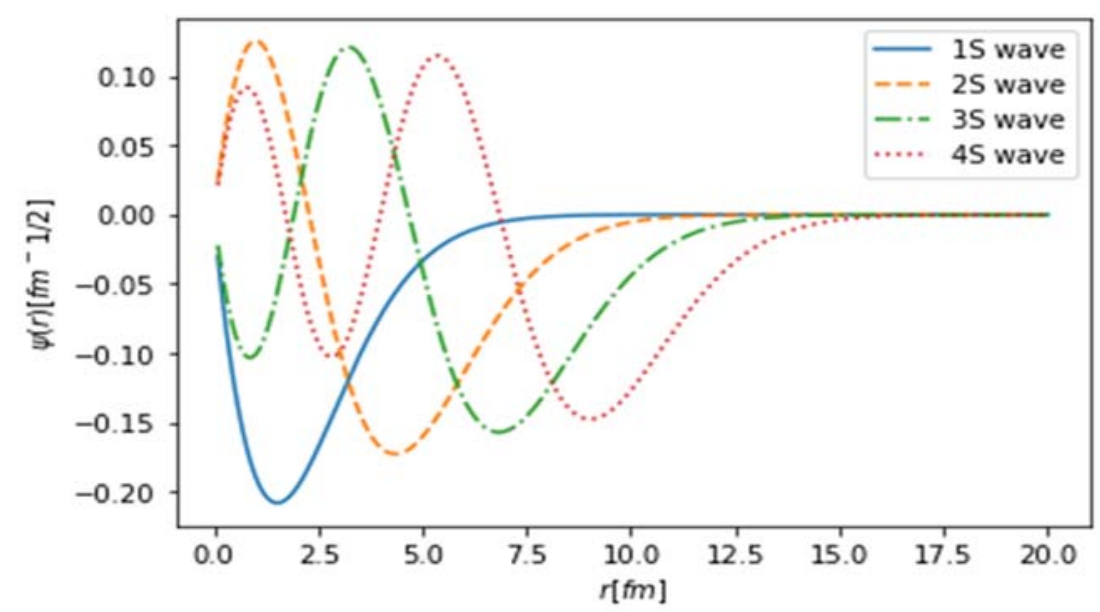

Figure 1. Charmonium S-states reduced radial wave functions.

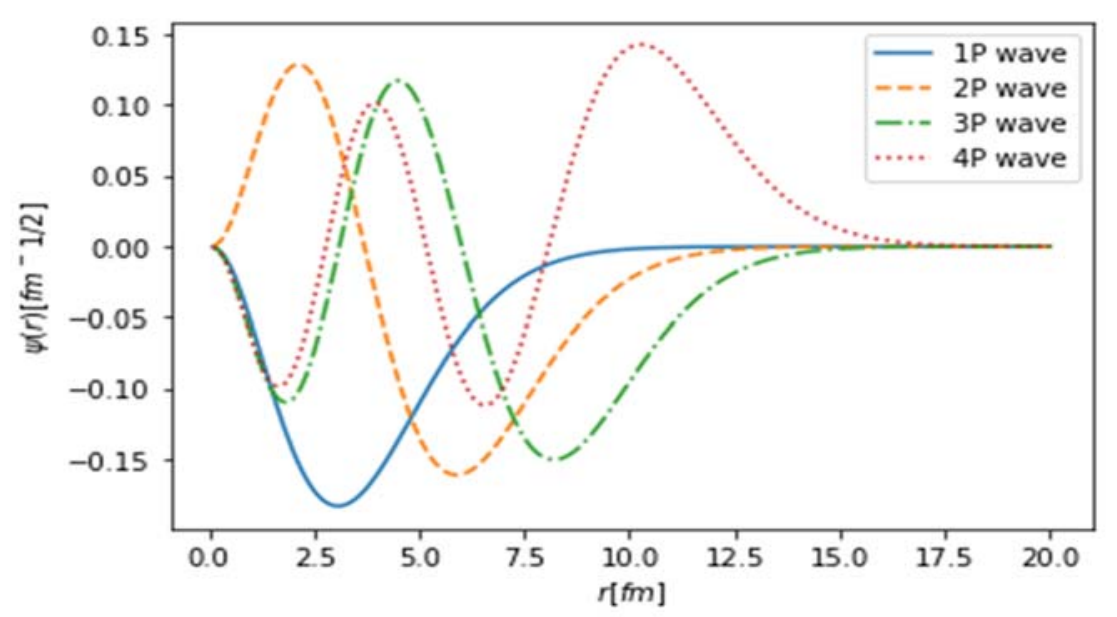

Figure 2. Charmonium P-states reduced radial wave functions. 
In Figure (3), the present potential has been plotted for $\mathrm{S}$ and $\mathrm{P}$ states of charmonium. The predictions about the values of momentum width (Coefficient $\beta$ ) for charmonium $S$ and $P$ States in comparison between our results and those obtained in previous calculations $[20,21]$ are reported in Tables $(3,4)$ respectively.

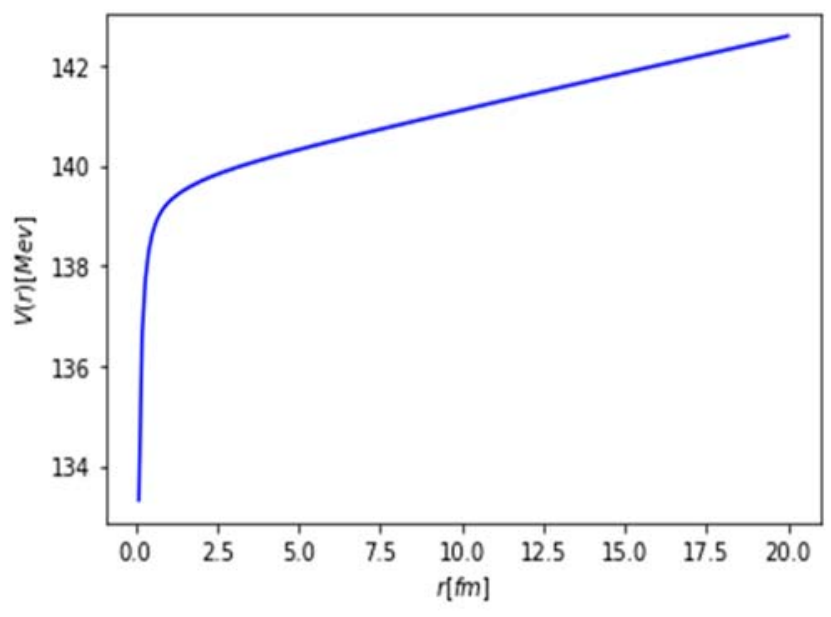

a

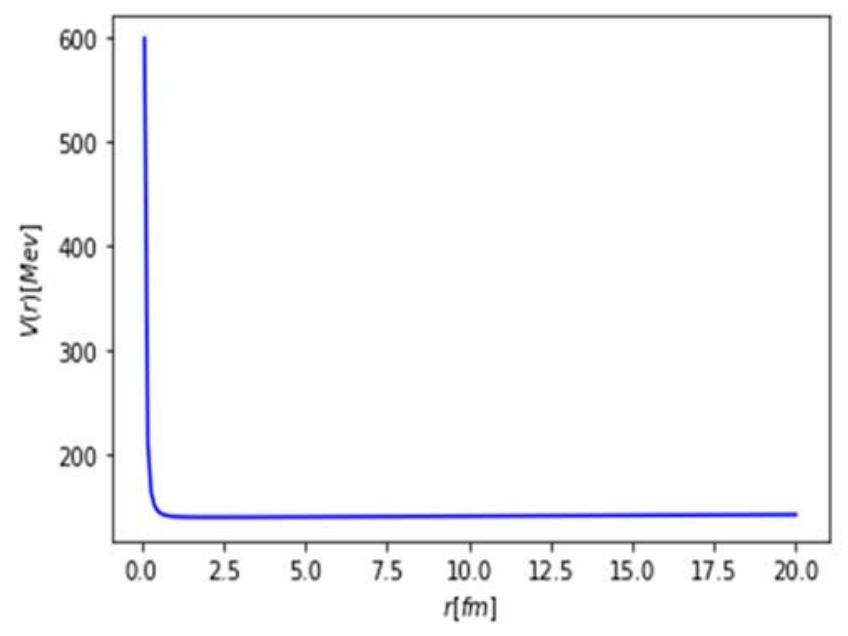

b

Figure 3. The present potential of charmonium meson for S and P States.

(a) - The present potential of charmonium meson for S States, (b) - The present potential of charmonium meson for P States

Mass spectrum for $c \bar{c}$ meson of S- states (in GeV) using matrix method.

Table 1.

\begin{tabular}{|c|c|c|c|c|c|c|c|c|c|}
\hline \multicolumn{7}{|c|}{ State } & Matrix \\
method & {$[15]$} & {$[16]$} & PDG [17] \\
\hline $\mathrm{n}$ & $\mathrm{L}$ & $\mathrm{S}$ & $\mathrm{J}$ & $\mathrm{J}^{\mathrm{PC}}$ & Meson & & & \\
\hline $1^{1} \mathrm{~S}_{0}$ & 0 & 0 & 0 & $\mathbf{0}^{-+}$ & $\eta_{c}(1 s)$ & 3.017 & 2.9816 & 3.004 & $2.9810 \pm 0.0011$ \\
\hline $1^{3} \mathrm{~S}_{1}$ & 0 & 1 & 1 & $\mathbf{1}^{--}$ & $\mathrm{J} / \Psi$ & 3.113 & 3.0900 & 3.086 & $3.096916 \pm 0.000011$ \\
\hline $2^{1} \mathrm{~S}_{0}$ & 0 & 0 & 0 & $\mathbf{0}^{-+}$ & $\eta_{c}(2 s)$ & 3.637 & 3.6303 & 3.645 & $3.6389 \pm 0.0013$ \\
\hline $2^{3} \mathrm{~S}_{1}$ & 0 & 1 & 1 & $\mathbf{1}^{--}$ & $\psi(2 \mathrm{~S})$ & 3.678 & 3.6718 & 3.708 & $3.6861 \pm 0.000012$ \\
\hline $3^{1} \mathrm{~S}_{0}$ & 0 & 0 & 0 & $\mathbf{0}^{-+}$ & $\eta_{c}(3 s)$ & 4.047 & 4.0432 & 4.124 & \\
\hline $3^{3} \mathrm{~S}_{1}$ & 0 & 1 & 1 & $\mathbf{1}^{--}$ & $\psi(4040)$ & 4.076 & 4.0716 & 4.147 & $4.040 \pm 10$ \\
\hline $4^{1} \mathrm{~S}_{0}$ & 0 & 0 & 0 & $\mathbf{0}^{-+}$ & $\eta_{c}(4 s)$ & 4.388 & 4.3837 & 4.534 & \\
\hline${ }^{3} \mathrm{~S}_{1}$ & 0 & 1 & 1 & $\mathbf{1}^{--}$ & $\psi(4415)$ & 4.411 & 4.4061 & 4.579 & \\
\hline
\end{tabular}


Table 2.

Mass spectrum of radially excited states (P-States) of $\mathrm{c} \overline{\mathrm{C}}$ meson (in $\mathrm{GeV}$ ) using matrix method.

\begin{tabular}{|c|c|c|c|c|c|c|c|c|c|}
\hline \multicolumn{6}{|c|}{ State } & \multirow[t]{2}{*}{ Matrix method } & \multirow[t]{2}{*}[15]{} & \multirow[t]{2}{*}{ [16] } & \multirow[t]{2}{*}{ PDG [17] } \\
\hline $\mathrm{n}$ & $\mathrm{L}$ & S & $\mathrm{J}$ & $\mathrm{J}^{\mathrm{PC}}$ & Meson & & & & \\
\hline $1^{1} \mathrm{P}_{1}$ & 1 & 0 & 1 & $\mathbf{1}^{+-}$ & $h_{c}(1 \mathcal{P})$ & 3.545 & 3.5156 & 3.496 & $3.52541 \pm 0.00016$ \\
\hline $1^{3} \mathrm{P}_{1}$ & 1 & 1 & 1 & $\mathbf{1}^{++}$ & $\chi_{c 1}(1 \mathcal{P})$ & 3.524 & 3.5054 & 3.492 & $3.51066 \pm 0.00007$ \\
\hline $1^{3} \mathrm{P}_{2}$ & 1 & 1 & 2 & $2^{++}$ & $\chi_{c 2}(1 \mathcal{P})$ & 3.543 & 3.5490 & 3.511 & $3.556 \pm 0.009$ \\
\hline $2^{1} \mathrm{P}_{1}$ & 1 & 0 & 1 & $\mathbf{1}^{+-}$ & $Z_{c}(3900)$ & 3.958 & 3.9336 & 3.991 & \\
\hline $2^{3} \mathrm{P}_{1}$ & 1 & 1 & 1 & $\mathbf{1}^{++}$ & $\chi_{c 1}(3872)$ & 3.94 & 3.9249 & 3.984 & \\
\hline $2^{3} \mathrm{P}_{2}$ & 1 & 1 & 2 & $2^{++}$ & $\chi_{c 2}(3990)$ & 3.959 & 3.9648 & 4.007 & $3.927 \pm 0.026$ \\
\hline $3^{1} \mathrm{P}_{1}$ & 1 & 0 & 1 & $\mathbf{1}^{+-}$ & $X(4020)$ & 4.303 & 4.2793 & 4.410 & \\
\hline $3^{3} \mathrm{P}_{1}$ & 1 & 1 & 1 & $1^{++}$ & $\chi_{c 1}(4140)$ & 4.285 & 4.2707 & 4.401 & \\
\hline $3^{3} \mathrm{P}_{2}$ & 1 & 1 & 2 & $2^{++}$ & $\chi_{C 2}(3 \mathcal{P})$ & 4.306 & 4.3093 & 4.427 & $4.350 \pm 0.007$ \\
\hline $4{ }^{1} \mathrm{P}_{1}$ & 1 & 0 & 1 & $\mathbf{1}^{+-}$ & $Z_{c}(4430)$ & 4.61 & 4.5851 & 4.784 & \\
\hline $4^{3} \mathrm{P}_{1}$ & 1 & 1 & 1 & $\mathbf{1}^{++}$ & $\chi_{c 1}(4274)$ & 4.592 & 4.5762 & 4.771 & \\
\hline $4^{3} \mathrm{P}_{2}$ & 1 & 1 & 2 & $2^{++}$ & $\chi_{C 2}(4 \mathcal{P})$ & 4.613 & 4.6141 & 4.802 & \\
\hline
\end{tabular}

Table 3.

Momentum width (Coefficient $\beta$ ) of ground states of charmonium mesons using matrix method.

\begin{tabular}{|c|c|c|c|c|c|c|c|c|}
\hline \multicolumn{6}{|c|}{ State } & \multirow{2}{*}{ Our work } & \multirow{2}{*}[20]{} & \multirow{2}{*}{ [21] } \\
\hline $\mathrm{n}$ & $\mathrm{L}$ & $\mathrm{S}$ & $\mathrm{J}$ & $\mathrm{J}^{\mathrm{PC}}$ & Meson & & & \\
\hline $1^{1} \mathrm{~S}_{0}$ & 0 & 0 & 0 & $\mathbf{0}^{-+}$ & $\eta_{c}(1 s)$ & 0.633 & 0.615 & 0.6642 \\
\hline $1^{3} \mathrm{~S}_{1}$ & 0 & 1 & 1 & $\mathbf{1}^{--}$ & $\mathrm{J} / \psi$ & 0.562 & 0.596 & 0.5666 \\
\hline $2^{1} \mathrm{~S}_{0}$ & 0 & 0 & 0 & $\mathbf{0}^{-+}$ & $\eta_{c}(2 s)$ & 0.436 & 0.435 & 0.4456 \\
\hline $2^{3} \mathrm{~S}_{1}$ & 0 & 1 & 1 & $\mathbf{1}^{--}$ & $\psi(2 S)$ & 0.421 & 0.431 & 0.4249 \\
\hline $3^{1} \mathrm{~S}_{0}$ & 0 & 0 & 0 & $\mathbf{0}^{-+}$ & $\eta_{c}(3 s)$ & 0.38 & 0.38 & 0.3858 \\
\hline $3^{3} \mathrm{~S}_{1}$ & 0 & 1 & 1 & $\mathbf{1}^{--}$ & $\psi(4040)$ & 0.373 & 0.378 & 0.3763 \\
\hline $4^{1} \mathrm{~S}_{0}$ & 0 & 0 & 0 & $\mathbf{0}^{-+}$ & $\eta_{c}(4 s)$ & 0.351 & 0.351 & 0.3555 \\
\hline $4^{3} \mathrm{~S}_{1}$ & 0 & 1 & 1 & $\mathbf{1}^{--}$ & $\psi(4415)$ & 0.347 & 0.35 & 0.3499 \\
\hline
\end{tabular}


Table 4.

Momentum width (Coefficient $\beta$ ) of radially excited states of charmonium mesons using matrix method.

\begin{tabular}{|c|c|c|c|c|c|c|c|c|}
\hline \multicolumn{6}{|c|}{ State } & \multirow{2}{*}{ Our work } & \multirow{2}{*}[20]{} & \multirow{2}{*}[21]{} \\
\hline $\mathrm{n}$ & $\mathrm{L}$ & $\mathrm{S}$ & $\mathrm{J}$ & $\mathrm{J}^{\mathrm{PC}}$ & Meson & & & \\
\hline $1^{1} \mathrm{P}_{1}$ & 1 & 0 & 1 & $1^{+-}$ & $h_{c}(1 \mathcal{P})$ & 0.437 & 0.458 & 0.3487 \\
\hline $1^{3} \mathrm{P}_{1}$ & 1 & 1 & 1 & $1^{++}$ & $\chi_{c 1}(1 \mathcal{P})$ & 0.455 & 0.471 & 0.3487 \\
\hline $1^{3} \mathrm{P}_{2}$ & 1 & 1 & 2 & $2^{++}$ & $\chi_{c 2}(1 \mathcal{P})$ & 0.432 & 0.439 & 0.3487 \\
\hline $2^{1} \mathrm{P}_{1}$ & 1 & 0 & 1 & $1^{+-}$ & $Z_{c}(3900)$ & 0.379 & 0.389 & \\
\hline $2^{3} \mathrm{P}_{1}$ & 1 & 1 & 1 & $1^{++}$ & $\chi_{c 1}(3872)$ & 0.387 & 0.394 & \\
\hline $2^{3} \mathrm{P}_{2}$ & 1 & 1 & 2 & $2^{++}$ & $\chi_{c 2}(3990)$ & 0.376 & 0.38 & \\
\hline $3^{1} \mathrm{P}_{1}$ & 1 & 0 & 1 & $1^{+-}$ & $X(4020)$ & 0.35 & 0.356 & \\
\hline $3^{3} \mathrm{P}_{1}$ & 1 & 1 & 1 & $1^{++}$ & $\chi_{c 1}(4140)$ & 0.356 & 0.359 & \\
\hline $3^{3} \mathrm{P}_{2}$ & 1 & 1 & 2 & $2^{++}$ & $\chi_{C 2}(3 \mathcal{P})$ & 0.348 & 0.351 & \\
\hline $4^{1} \mathrm{P}_{1}$ & 1 & 0 & 1 & $\mathbf{1}^{+-}$ & $Z_{c}(4430)$ & 0.331 & & \\
\hline $4^{3} \mathrm{P}_{1}$ & 1 & 1 & 1 & $1^{++}$ & $\chi_{c 1}(4274)$ & 0.336 & & \\
\hline $4^{3} \mathrm{P}_{2}$ & 1 & 1 & 2 & $2^{++}$ & $\chi_{C 2}(4 \mathcal{P})$ & 0.33 & & \\
\hline
\end{tabular}

\section{Conclusion}

The non-relativistic quark model is one of the most powerful frameworks to investigate the heavy meson spectra. The mass spectra of $c \bar{c}$ mesons were calculated in that framework based on the matrix method. Predictions from our method are found to be in good agreement with the PDG results and available theoretical results. Our results in comparison with the experimental data and other theoretical approaches results are reported in Tables $(1,2)$. It can be noticed that our calculated mass spectra are in close resemblance with the latest PDG results and also with the results of other theoretical studies, thus it can be concluded that this method gives satisfying results for $\mathrm{S}$ and $\mathrm{P}$ wave spectroscopy. On the other hand, we used the matrix method to obtain the radial wave functions of charmonium meson to calculate the coefficient $\beta$. Then, we compare our results with available published results which obtained from other studies and it was nearly commensurate. Our calculated coefficient $\beta$ in comparison with other theoretical studies are reported in Tables $(3,4)$. As a remarkable result, we can point out that it is recommended to use the obtained values of coefficient $\beta$ to calculate the decay widths and differential cross sections for charmonium system. Overall, the obtained results from the present study are reasonable when compared with the latest experimental results and available theoretical results which obtained from other approaches for the mass spectra of $c \bar{c}$ meson.

Finally, we may notice that the calculated values of coefficient $\beta$ are the newer outputs where we did not find experimental data for comparison. So, we are looking forward to taking these data in consideration by other experimental and theoretical researchers.

Tarek A. Nahool https://orcid.org/0000-0002-3967-0103

\section{ORCID IDs}

REFERENCES

[1] T. Barnes, S. Godfrey, and E.S. Swanson, Physical Review D, 72(5), 054026 (2005), https://doi.org/10.1103/PhysRevD.72.054026. 
[2] H.X. Chen, W. Chen, X. Liu, and S.L. Zhu, Phys. Rep. 639, 1-121 (2016), https://doi.org/10.1016/j.physrep.2016.05.004.

[3] X.L. Wang et al. (Belle Collaboration), Phys. Rev. Lett. 99, 142002 (2007), https://doi.org/10.1103/PhysRevLett.99.142002.

[4] C. McNeile, C.T.H. Davies, E. Follana, K. Hornbostel, and G.P. Lepage (HPQCD Collaboration), Phys. Rev. D, 86, 074503 (2012), https://arxiv.org/abs/1207.0994, https://doi.org/10.1103/PhysRevD.86.074503.

[5] M. Neubert, Phys. Rep. 245(5-6), 259-395 (1994), https://doi.org/10.1016/0370-1573(94)90091-4.

[6] S. Godfrey, and N. Isgur, Phys. Rev. D, 32, 189 (1985), https://doi.org/10.1103/PhysRevD.32.189.

[7] C. Semay, and B. Silvestre-Brac, Nuclear Physics A, 618, 455-482 (1997), https://doi.org/10.1016/S0375-9474(97)00060-2.

[8] G. Bhanot, and S. Rudaz, Phys. Lett. B, 78, 119-124 (1978), https://doi.org/10.1016/0370-2693(78)90362-3.

[9] N. Brambilla, and A. Vario, Acta. Phys. Polon. B, 38, 3429 (2007).

[10] S.S. Gershtein, V.V. Kiselev, A.K. Likhoded, and A.V. Tkabladze, Phys. Rev. D, 51, 3613 (1995), https://doi.org/10.1103/PhysRevD.51.3613.

[11] Bhaghyesh, K.B.V. Kumar, and M. Yong-Liang, Int. J. Mod. Phys. A, 27, 125001 (2009).

[12] A. B. Henriques, Z. Phys. C, Particles and Fields, 18, 213 (1983), https://doi.org/10.1007/BF01571362.

[13] A.M. Yasser, G.S. Hassan, and T.A. Nahool, Journal of Modern Physics, 5, 1938-1944 (2014). http://dx.doi.org/10.4236/jmp.2014.517188

[14] T.A. Nahool, A.M. Yasser and G.S. Hassan, EJTP, 12(32), 113-120 (2015).

[15] M. Atif Sultan, Nosheen Akbar, Bilal Masud, and Faisal Akram, Phys. Rev. D, 90, 054001 (2014), https://doi.org/10.1103/PhysRevD.90.054001.

[16] Raghav Chaturvedi and Ajay Kumar Rai, Eur. Phys. J. Plus, 133(220) (2018), https://doi.org/10.1140/epjp/i2018-12044-8.

[17] C. Patrignani et al. (Particle Data Group), Chin. Phys. C, 40, 100001 (2016).

[18] B. Patel, and P.C. Vinodkumar, Journal of Physics G, 36, Article ID: 035003, (2009), http://dx.doi.org/10.1088/09543899/36/3/035003.

[19] C.H. Chaug, C.F Qiao and J.X. Wang, Physical Review D, 57, Article ID: 4035, (1998). http://dx.doi.org/10.1103/PhysRevD.57.4035

[20] A.S. Ahmed, Studying of Some Charmonium Properties by Using Matrix Method, M.Sc. Thesis, South Valley University, Egypt, (2014).

[21] Jamil Ahmed, Rahila Manzoor and Alfredo Raya, Quant. Phys. Lett. 6(2), 99-103 (2017). http://dx.doi.org/10.18576/qpl/060204

[22] B. Jonsson and S. T. Eng, IEEE journal of quantum electronics, 26(11), 2025-2035 (1990).

[23] O. Lakhina, and E.S. Swanson, (2006) Physical Review D, 74, Article ID: 014012. http://dx.doi.org/10.1103/PhysRevD.74.014012.

[24] N. Akbar, B. Masud, and S. Noor, The European Physical Journal A, 50(7), 121 (2014), https://doi.org/10.1140/epja/i2014-14121-y.

[25] T. Barnes and G. I. Ghandour, Phys. Lett, B, 118, 411-413 (1982), https://doi.org/10.1016/0370-2693(82)90214-3.

[26] A.A. Aly, Heavy Meson Spectra Non-Relativistic Quark Model, M. Sc. Thesis, (South Valley University, 2012).

[27] J. Förster, A. Saenz, and Ul. Wolff, Phys. Rev. E, 86, 016701 (2012), https://doi.org/10.1103/PhysRevE.86.016701.

[28] Cheuk-Yin Wong, Phys. Rev. C, 69, 055202, (2004), https://doi.org/10.1103/PhysRevC.69.055202.

\section{ВЛАСТИВОСТІ ЧАРМОНІЮ}

Тарек А. Нагула , А.М. Ясер ${ }^{\text {, Мохаммад Анвара }}$, Гамаль А. Яхья

аДепартамент фізики, Науковий факультет, Асуанський університет, Сгипет

вдепартамент фізики, Науковий факультет Кени, Університет Південної долини, Сгипет

Ми розрахували мас-спектри мезона чармонію за допомогою матричного методу, щоб зробити передбачення основного і радіально збудженого станів мезонів чармонію за допомогою нерелятивістської потенційної моделі. Ми порівняли наші результати з іншими теоретичними підходами і недавно опублікованими експериментальними даними. Виявлено, що передбачення знаходяться в хорошому відповідно до останніх експериментальними результатами групи даних частинок і 3 результатами інших теоретичних підходів. Крім того, були розраховані коефіцієнти ширини імпульсу $\beta$ мезона чармонію. Оскільки експериментальних даних для коефіцієнтів ширини імпульсу $\beta$ мезона чармонію поки немає, тому наші розраховані коефіцієнти $\beta$ порівнюються з іншими теоретичними дослідженнями, і показано, що вони добре узгоджуються 3 нашими результатами. Отримані результати за коефіцієнтами $\beta$ мають значення для констант розпаду, ширин розпаду $\mathrm{i}$ диференціальних перерізів для системи чармонію і в цілому для системи важких мезонів. Наше дослідження розглядається як теоретичний розрахунок деяких властивостей мезона чармонію.

КЛЮЧОВІ СЛОВА: важкі мезони, матричний метод, чармоній, ширина імпульсу

\section{СВОЙСТВА ЧАРМОНИЯ}

Тарек А. Нагул ${ }^{\mathrm{a}}$, А.М. Ясер ${ }^{\mathrm{b}}$, Мухаммад Анвар ${ }^{\mathrm{a}}$, Гамаль А. Яхья

аДепарталент физики Научный факультет, Асуанский университет, Египет

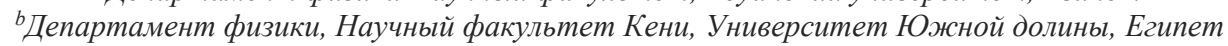

Мы рассчитали масс-спектры мезона чармония с помощью матричного метода, чтобы сделать предсказания основного и радиально возбужденного состояний мезонов чармония с помощью нерелятивистской потенциальной модели. Мы сравнили наши результаты с другими теоретическими подходами и недавно опубликованными экспериментальными данными. Обнаружено, что предсказания находятся в хорошем соответствии с последними экспериментальными результатами группы данных частиц и с результатами других теоретических подходов. Кроме того, были рассчитаны коэффициенты ширины импульса $\beta$ мезона чармония. Поскольку экспериментальных данных для коэффициентов ширины импульса $\beta$ мезона чармония пока нет, поэтому наши рассчитанные коэффициенты $\beta$ сравниваются с другими теоретическими исследованиями, и показано, что они хорошо согласуются с нашими результатами. Полученные результаты по коэффициентам $\beta$ имеют значение для констант распада, ширин распада и дифференциальных сечений для системы чармония и в целом для системы тяжелых мезонов. Наше исследование рассматривается как теоретический расчет некоторых свойств мезона чармония.

КЛЮЧЕВЫЕ СЛОВА: тяжелые мезоны, матричный метод, чармоний, ширина импульса 